\title{
Multielectrode phased radiofrequency ablation compared with point-by-point ablation for pulmonary vein isolation - outcomes in 539 patients
}

\author{
This article was published in the following Dove Press journal: \\ Research Reports in Clinical Cardiology \\ 16 January 2014 \\ Number of times this article has been viewed
}

\section{Stefan G Spitzer' \\ Laszlo Karolyi' \\ Thomas Weinmann' \\ Frank Scharfe' \\ Carola Rämmler' \\ Tobias Otto' \\ Friedrich Jung ${ }^{2}$ \\ Clemens T Kadalie \\ 'Praxisklinik Herz und Gefäße, Akademische Lehrpraxisklinik der TU Dresden, Dresden, Germany; ${ }^{2}$ Saarland University, Homburg, Saar, Germany}

Correspondence: Stefan G Spitzer Praxisklinik Herz und Gefäße, Akademische Lehrpraxisklinik der TU Dresden, Forststraße 3, D - 01099

Dresden, Germany

Tel +493518064115

Fax +49 35I 8064110

Email buero-spitzer@praxisklinik-

dresden.de
Purpose: To provide data on acute and long-term outcomes from pulmonary vein isolation with the pulmonary vein ablation catheter (PVAC) in patients with paroxysmal or persistent atrial fibrillation (AF).

Methods: This was a single-center, retrospective, nonrandomized, case control study. Patients with documented symptomatic paroxysmal or persistent AF were treated with PVAC or with pointby-point radiofrequency ablation guided by the Nav $\mathrm{X}^{\mathrm{TM}}$ mapping system. All follow-up visits were conducted in our center at 1 month, 3 months, and 6 months, and then at 6-month intervals. Electrocardiography and 24-hour Holter monitoring were performed at each follow-up visit. The endpoints included procedure times, acute and 24-month outcomes, and complications.

Results: Of the 539 patients that were enrolled consecutively, 388 were ablated using PVAC and 151 using radiofrequency ablation. More patients with paroxysmal AF were treated with PVAC than with radiofrequency ablation. Acute success rates were $>99 \%$ with both methods. Procedure duration and fluoroscopy times were significantly $(P<0.001)$ shorter with PVAC than with point-by-point ablation. Rates of freedom from $\mathrm{AF}$ at all follow-up times available (up to 24 months) were significantly higher after PVAC ablation than with radiofrequency ablation (64.2\% versus $48.2 \%$ at 24 months). With both ablation strategies, the rates of freedom from $\mathrm{AF}$ were higher in patients with paroxysmal AF than for persistent AF. Two posterior cerebral infarcts occurred in the PVAC group within 2 days of the procedure. No phrenic nerve injuries and no esophageal injuries were recorded. Data on embolic lesions were not collected.

Conclusion: PVAC ablation achieved higher 24-month rates of AF-free survival than conventional radiofrequency ablation. Procedure and fluoroscopy times were shorter with PVAC, although the differences between groups may have influenced the results.

Keywords: arrhythmia, atrial fibrillation, catheter ablation, pulmonary vein isolation, longterm follow-up, safety

\section{Introduction}

Atrial fibrillation (AF) is the most common cardiac arrhythmia in the general population. ${ }^{1,2}$ Estimated prevalence rates range between $1 \%$ and $2 \%$, and true rates including asymptomatic AF may be significantly higher than the diagnosed rates. ${ }^{3}$ Circumferential pulmonary vein isolation (PVI) by irrigated point-by-point radiofrequency $(\mathrm{RF})$ catheter ablation is a highly effective intervention against $\mathrm{AF}$ at the paroxysmal AF (PAF) stage. In persistent AF, additional linear ablations are often needed to increase success rates and to improve long-term outcomes. ${ }^{4}$ 
The pulmonary vein ablation catheter (PVAC) $)^{5,6}$ was developed as an alternative to conventional RF ablation - in particular, to overcome the recognized difficulties in generating contiguous transmural lesions with a single-point catheter. PVAC is based on anatomically designed catheters that enable circumferential ablation across a wide area, encircling the pulmonary vein (PV) antrum without the use of additional sophisticated mapping systems to guide ablation.

Available data comparing PVAC with irrigated pointby-point RF ablation suggest similar acute and short-term ablation success rates with both methods in patients with paroxysmal or persistent AF. ${ }^{5,7}$ However, the number of patients in published reports remains limited; there are few publications that outline experiences with PVAC under conditions of actual care, and comparisons with Carto $^{\circledR}$ (Biosense Webster, Inc., Diamond Bar, CA, USA) and NavX $\mathrm{X}^{\mathrm{TM}}$ (St Jude Medical, Inc., Saint Paul, MN, USA) are rare. ${ }^{9,10}$ In addition, there are few data available on the technology in patients with persistent or long-lasting AF. As with all recent technologies, more studies with long-term follow-up are needed.

The aim of the present study was to perform a retrospective analysis of AF ablation procedures with PVAC and conventional RF catheter ablation for PVI in patients with paroxysmal or persistent AF treated at our center between 2005 and 2011. The endpoints included acute and longterm outcomes (over $>24$ months), procedure times, and complications.

\section{Methods}

\section{Study design}

This was a retrospective, nonrandomized, case controlled study conducted in patients treated at our center between October 1, 2005 and December 31, 2011. The study was conducted in compliance with Good Clinical Practice guidelines and consistent with the Declaration of Helsinki. ${ }^{11}$ All patients provided written, informed consent.

Patients had documented symptomatic paroxysmal or persistent AF with a history of failed treatment with $\geq 1$ antiarrhythmic drug. None of the patients had undergone ablation for AF previously. All patients were screened with cardiac computed tomography (CT) to define the PV anatomy and to exclude the contraindications for ablation used at our center (a significant reduction in left/right ventricular systolic function, coronary heart disease, tachycardia-mediated cardiomyopathy, left atrial [LA] appendage thrombus, atrial enlargement $>55 \mathrm{~mm}$, or mitral insufficiency higher than grade 2). Patients were enrolled consecutively and were treated with
PVAC or conventional point-by-point ablation guided by the NavX mapping with the choice in each individual case at the discretion of the treating physician. There was no protocol that detailed standardized recommendations.

\section{PVAC}

The PVAC is an over-the-wire, circular, decapolar mapping and RF ablation catheter with a $25 \mathrm{~mm}$ diameter array at the distal tip. The diameter of the electrode array can be increased or decreased by engaging the array against anatomical structures, allowing for the creation of circular lesions around up to ten electrodes. Rotating the catheter shaft changes the diameter of the array, enabling ablation around smaller or larger veins. PVAC is employed together with a multichannel RF generator (GENius; Medtronic, Minneapolis, MN, USA) that enables synchronous uni- and bipolar RF energy delivery to any combination of PVAC electrodes. ${ }^{7,8}$ Mapping is performed by bipolar recordings through adjacent electrode pairs.

\section{PVAC procedures}

Oral anticoagulation was stopped before the procedures, and low-molecular weight heparin was used as a bridging anticoagulant. Intravenous heparin was used during the procedures to maintain an activated clotting time $>300$ seconds. After a single transseptal puncture, a fixed-curve, long $10 \mathrm{~F}$ sheath (Frontier Advance; Medtronic) was inserted into the LA. Angiography with selective contrast injection was performed to visualize the PV ostia.

The PVAC was inserted via the $10 \mathrm{~F}$ sheath. A 0.032 inch guide wire was placed inside the PV and was used to advance the catheter until it was wedged within the antrum, proximal to the ostium, to record local electrical activity at the veno-atrial junction prior to RF energy application. When the PV fit the diameter of the PVAC, the catheter was pushed against the $\mathrm{PV}$ antrum. In cases where a large PV ostium or a common ostium was noted, the PVAC was sequentially repositioned around the ostium of the PV or at the antral site of the common ostium to achieve PVI. Prior to ablation, electrical signals from all veno-atrial junctions were recorded using the PVAC to provide reference PVAC signals for the recordings made after every RF application. RF energy was delivered with the GENius generator. Energy was applied in a 4:1 bipolar/unipolar ratio initially, titrated to $2: 1$ as necessary if the PV potentials were not eliminated. Energy was delivered in a temperaturecontrolled, power-limited manner with maximally $10 \mathrm{~W}$ per electrode. Each energy application lasted for 60 seconds with a temperature target of $60^{\circ} \mathrm{C}$ for each electrode in the selected 
pairs. If the temperature did not rise above $50^{\circ} \mathrm{C}$ within 15 seconds, or in case of power oscillation, the application was discontinued and the position improved.

All PVs were mapped with the PVAC 15-30 minutes post-ablation. $\mathrm{PV}$ isolation was defined as entrance and exit blocks (Figure 1). If PVs appeared to be incompletely isolated, additional RF applications were delivered until PV isolation was achieved based on PVAC signals. Patients who failed repeated ablation attempts (as defined by the treating physician) were put on antiarrhythmic drug regimens.

\section{Point-by point ablation}

Access to the LA was obtained with a single transseptal puncture. The three-dimensional (3D)-geometry of the LA was reconstructed using the EnSite ${ }^{\mathrm{TM}} \mathrm{NavX}^{\mathrm{TM}}$ and NavX $\mathrm{X}^{\mathrm{TM}}$ Fusion systems (St Jude Medical, Inc.). RF energy was applied to encircle the right and left PV guided by the NavX system using an externally-irrigated-tip catheter (Celsius ${ }^{\circledR}$ ThermoCool $^{\circledR}$; Biosense Webster, Inc.) and an EP-Shuttle generator (Stockert; Biosense Webster, Inc.). The applied power ranged from $20 \mathrm{~W}$ to a maximum of $35 \mathrm{~W}$, to target a maximal temperature of $45^{\circ} \mathrm{C}$.

Circumferential ablation was performed on the posterior wall $(>1 \mathrm{~cm})$ and on the anterior wall, $>5 \mathrm{~mm}$ away from the predefined $\mathrm{PV}$ ostia. In patients with persistent $\mathrm{AF}$, additional linear lesions at the LA roof and mitral isthmus were generated to eliminate additional arrhythmogenic substrate and to prevent large atrial re-entrant circuits. The diameter of the circumferential catheter was adjusted to the diameter of the $\mathrm{PV}$ antrum. Successful isolation of all four PVs was confirmed as an entrance and exit block. A complete block was defined as the presence of double potentials along the entire ablation line. ${ }^{12}$ Other details were the same as in the PVAC group.

\section{Follow-up and outcomes}

Patients were discharged from hospital 1-2 days after the procedure. Oral anticoagulation was administered to all patients for 3 months after the ablation procedure, targeting an internal
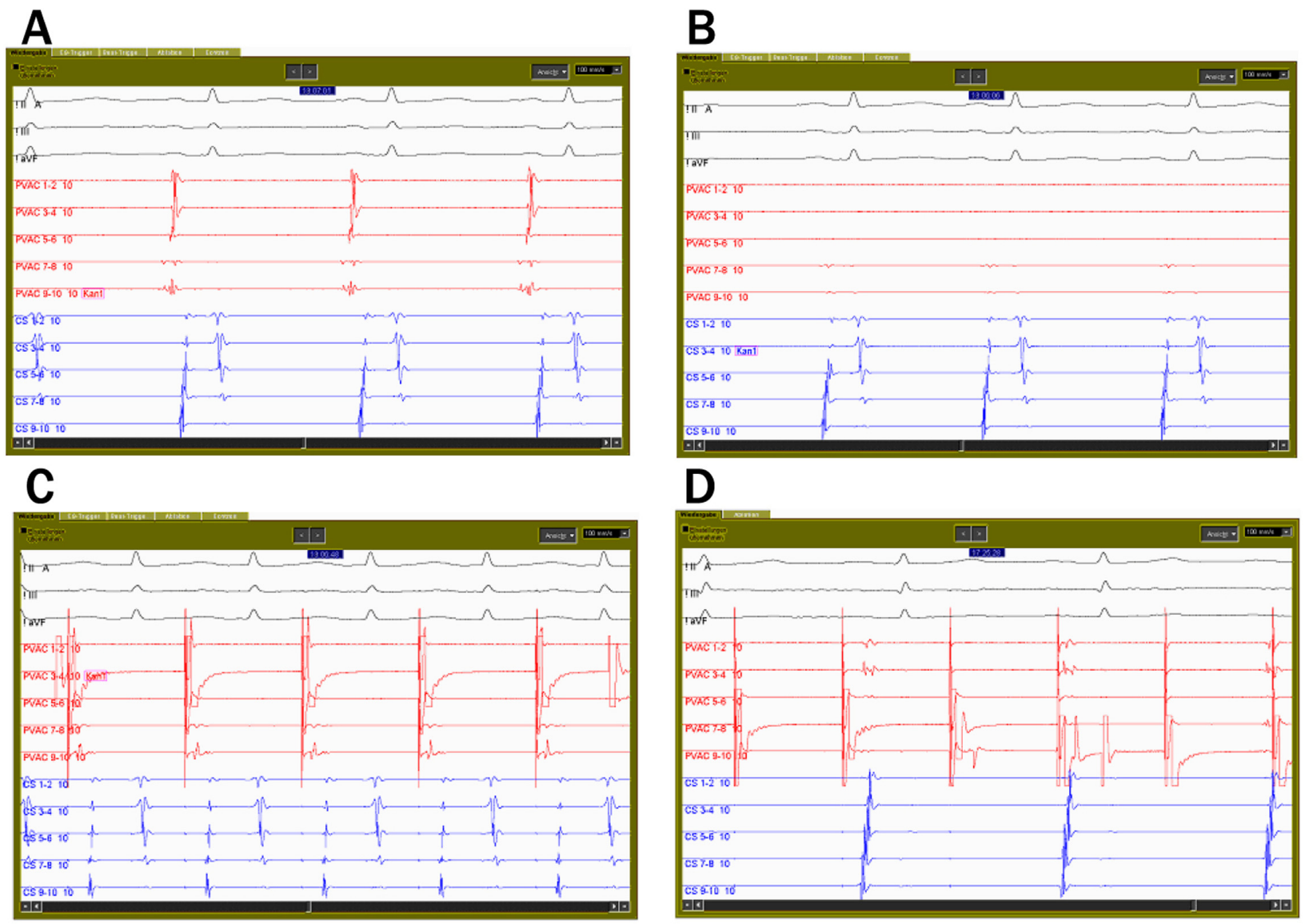

Figure I Pulmonary vein ablation catheter electrograms from the left inferior pulmonary vein.

Notes: (A) Conductance pattern before ablation; (B) entrance block demonstrated after successful ablation with pulmonary vein ablation catheter; (C) during stimulation before ablation; and (D) exit block demonstrated after successful ablation with pulmonary vein ablation catheter.

Abbreviations: CS, coronary sinus electrode; PVAC, pulmonary vein ablation catheter. 
normalized ratio of 2.0-3.0. All follow-up visits were held in our center, and they were scheduled at 1 month, 3 months, and 6 months, as well as at 6-monthly intervals thereafter. Electrocardiography and 24-hour Holter monitoring were performed to confirm sinus rhythm at each follow-up visit, consistent with the recommendations of the Heart Rhythm Society/European Heart Rhythm Association/European Cardiac Arrhythmia Society (HRS/EHRA/ECAS) expert Consensus Statement on catheter and surgical ablation of AF. ${ }^{13}$ In the PVAC group, redo ablation procedures were performed with PVAC. In the NavX group, and if a second redo procedure was necessary in both groups, point-by-point ablation and NavX was used. At the 12-month follow-up, a 4-day Holter was performed in addition to the 24-hour Holter monitoring in all patients. No event recorder was used. Antiarrhythmic medication was prescribed for patients with electrocardiography- or 4-day Holter-documented AF recurrence.

The primary outcome was maintained sinus rhythm with freedom from AF recurrence. This was defined as a sinus rhythm with no AF of $>30$ seconds duration documented on a 24-hour Holter, and no documented AF during the intervals between follow-up visits. Secondary outcomes were procedure times, number of RF applications, and peri- and post-procedural complications.

The majority of the procedures were conducted before concerns about the potential for subclinical embolic events during PVI were published. ${ }^{14}$ No brain magnetic resonance imaging (MRI) was carried out in our patients, but thromboembolic events were recorded in the safety analysis.

\section{Statistical procedures}

SPSS for Microsoft Windows (IBM Corporation, Armonk, NY, USA) was used for the statistical analyses. Continuous variables are expressed as means \pm standard deviations. Categorical variables are presented as percentages. Comparisons between the two groups were made with the $\chi^{2}$ test and the Student-Newman-Keuls test, as appropriate. A univariate logistic regression analysis was performed for the variables listed in Table 3. A multivariate logistic regression analysis was conducted, and it included the following variables: type of ablation; type of AF; atrial size; ejection faction; and number of ablations. For all analyses, a $P$-value $<0.05$ was considered statistically significant.

\section{Results}

A total of 539 patients were enrolled consecutively. The PVAC catheter was used in 388 patients and point-by-point ablation with NavX mapping in 151 patients - 68 of whom were treated utilizing the NavX Fusion system with integrated CT. Baseline characteristics are shown in Table 1. Patients treated with PVAC were, on average, older (average 61 years in the PVAC group versus 58 years in the NavX group), and they exhibited a greater prevalence of mitral insufficiency and a greater prevalence of PAF ( $80 \%$ in the PLAC group and $54 \%$ in the NavX group, respectively). There were no differences between the groups in terms of sex distribution, duration of AF, or LA size.

\section{Procedures}

On average, $17.5 \pm 4.5$ applications were needed in the PVAC group and 53.7 \pm 22.6 applications were needed in the NavX-guided ablation group (Table 2). In the NavX group, roof-line and LA isthmus ablation was performed in 54 patients; a box lesion and LA isthmus ablation were necessary in 81 patients. Acute success rates for PVI were $>99 \%$; only two right superior pulmonary veins and four right inferior pulmonary veins in the PVAC group could not be ablated due to their close proximity to the phrenic nerve. There were no differences in acute PVI success rates

Table I Baseline characteristics

\begin{tabular}{|c|c|c|c|}
\hline Variable & $\begin{array}{l}\text { NavX-guided } \\
\text { ablation } \\
(n=\mid 5 I)\end{array}$ & $\begin{array}{l}\text { PVAC } \\
\text { ablation } \\
(n=388)\end{array}$ & $P$-value \\
\hline Age years \pm SD & $58.1 \pm 9.3$ & $61.7 \pm 9.7$ & $<0.0001$ \\
\hline Male sex, n (\%) & $107(70.8 \%)$ & $249(64.2 \%)$ & 0.17 \\
\hline Hypertension, n (\%) & $73(48.3 \%)$ & I 47 (37.9\%) & 0.03 \\
\hline LA size $\mathrm{mm} \pm \mathrm{SD}$ & $43 \pm 5$ & $42 \pm 6$ & 0.02 \\
\hline LVEF $\% \pm$ SD & $53.4 \pm 7.2$ & $59.5 \pm 8.1$ & 0.54 \\
\hline $\begin{array}{l}\text { Mean duration of } A F \\
\text { years } \pm S D\end{array}$ & $1.79 \pm 3.5$ & $2.23 \pm 3.2$ & $<0.0001$ \\
\hline Type of AF n (\%) & & & $<0.000$ I \\
\hline Paroxysmal & 82 (54.3\%) & $310(79.9 \%)$ & \\
\hline Persistent & 47 (31.1\%) & $68(17.5 \%)$ & \\
\hline $\begin{array}{l}\text { Long-lasting (> | year) } \\
\text { persistent }\end{array}$ & $22(14.6 \%)$ & $10(2.6 \%)$ & \\
\hline $\begin{array}{l}\text { Coronary artery } \\
\text { disease, } n(\%)\end{array}$ & $19(12.6 \%)$ & 48 (I2.4\%) & 0.003 \\
\hline Cardiomyopathy, n (\%) & $6(4.0 \%)$ & $6(1.5 \%)$ & 0.1645 \\
\hline Mitral insufficiency, n (\%) & $88(58.3 \%)$ & $219(73.6 \%)^{a}$ & $<0.0001$ \\
\hline $\begin{array}{l}\text { Previous antiarrhythmic } \\
\text { medication, } \mathrm{n}(\%)\end{array}$ & $54(35.8 \%)$ & $198(51.0 \%)$ & \\
\hline Flecainide & 30 (19.9\%) & 83 (41.9\%) & \\
\hline Propafenone & $8(5.3 \%)$ & $23(11.9 \%)$ & \\
\hline Amiodarone & $14(9.2 \%)$ & $32(22.3 \%)$ & \\
\hline Dronedarone & $2(1.3 \%)$ & 59 (15.2\%) & \\
\hline Verapamil & 0 & $4(1.0 \%)$ & \\
\hline
\end{tabular}

Note: a Data were missing for nine patients.

Abbreviations: $n$, number; PVAC, pulmonary vein ablation catheter; SD, standard deviation; LA, left atrium; AF, atrial fibrillation; LVEF, left ventricular ejection fraction. 
Table 2 Procedural data

\begin{tabular}{|c|c|c|c|}
\hline & $\begin{array}{l}\text { NavX-guided } \\
\text { ablation }(n=|5|)\end{array}$ & $\begin{array}{l}\text { PVAC ablation } \\
(n=388)\end{array}$ & $P$-value \\
\hline $\begin{array}{l}\text { Procedure time } \\
\text { minute } \pm \text { SD }\end{array}$ & $142.2 \pm 35.0$ & $67.0 \pm 18.0$ & $<0.001$ \\
\hline $\begin{array}{l}\text { Fluoroscopy time } \\
\text { minute } \pm S D\end{array}$ & $29.3 \pm 9.8$ & $15.6 \pm 5.7$ & $<0.001$ \\
\hline $\begin{array}{l}\text { Number of } \\
\text { applications } \pm S D\end{array}$ & $53.7 \pm 22.6$ & $17.5 \pm 4.5$ & $<0.0001$ \\
\hline $\begin{array}{l}\text { Energy applied } \\
W / \text { second } \pm S D\end{array}$ & $46.0 \pm 16.1$ & $38.3 \pm 10.5$ & $<0.001$ \\
\hline
\end{tabular}

Abbreviations: $n$, number; PVAC, pulmonary vein ablation catheter; SD, standard deviation.

between the methods employed. The total duration of the procedure was significantly $(P<0.01)$ shorter with PVAC technology (67.0 \pm 18.0 minutes) than with point-by-point ablation (142.2 \pm 35.0 minutes). Differences were greatest for the ablation of PAF (67.4 \pm 18.2 minutes with PVAC versus 147.0 \pm 36.8 minutes with NavX), but a similar time advantage was observed for persistent AF (65.5 \pm 16.8 minutes with PVAC versus $136.5 \pm 31.9$ minutes with NavX). Notably, average fluoroscopy time with PVAC (15.6 \pm 5.7 minutes) was almost half that with NavX-guided ablation (29.3 \pm 9.8 minutes; $P<0.001$ for the comparison).

Follow-up data for $\geq 1$ month were available for all of the treated patients. In the NavX group, the mean follow-up was $51.9 \pm 13.4$ months and 89 patients were followed for 60 months. In the PVAC group, the average duration of follow-up was $15.6 \pm 10.4$ months and 161 patients were followed for 26 months.

Overall, redo ablation procedures in paroxysmal as well as persistent $\mathrm{AF}$ within 1 year of the initial procedure were necessary in 42 patients $(10.7 \%)$ treated with PVAC ablation and in 23 patients (15.1\%) treated with NavX-guided ablation, respectively. The differences were not significant. At 3 months, 6 months, and 12 months after PVAC ablation (including redo procedures), $70.0 \%, 67.9 \%$ and $64.0 \%$ of patients were free from $\mathrm{AF}$; the percentages of patients free from $\mathrm{AF}$ after NavX-guided ablation were $45.0 \%, 37.8 \%$, and $45.6 \%$ at the same time points, respectively ( $P<0.005$ for all comparisons; Figure 2A). The percentages of patients free from $\mathrm{AF}$ were maintained at 24 months (Figure 2A). These differences in outcomes were less emphasized among patients with PAF (Figure 2B), but in patients with persistent or permanent AF, the rates of freedom from AF with PVAC were consistently around twice those with NavX-guided ablation (Figure 2C). Because of the low numbers of patients in the subgroups with persistent/permanent AF, standard deviations were large and the differences were not statistically significant.
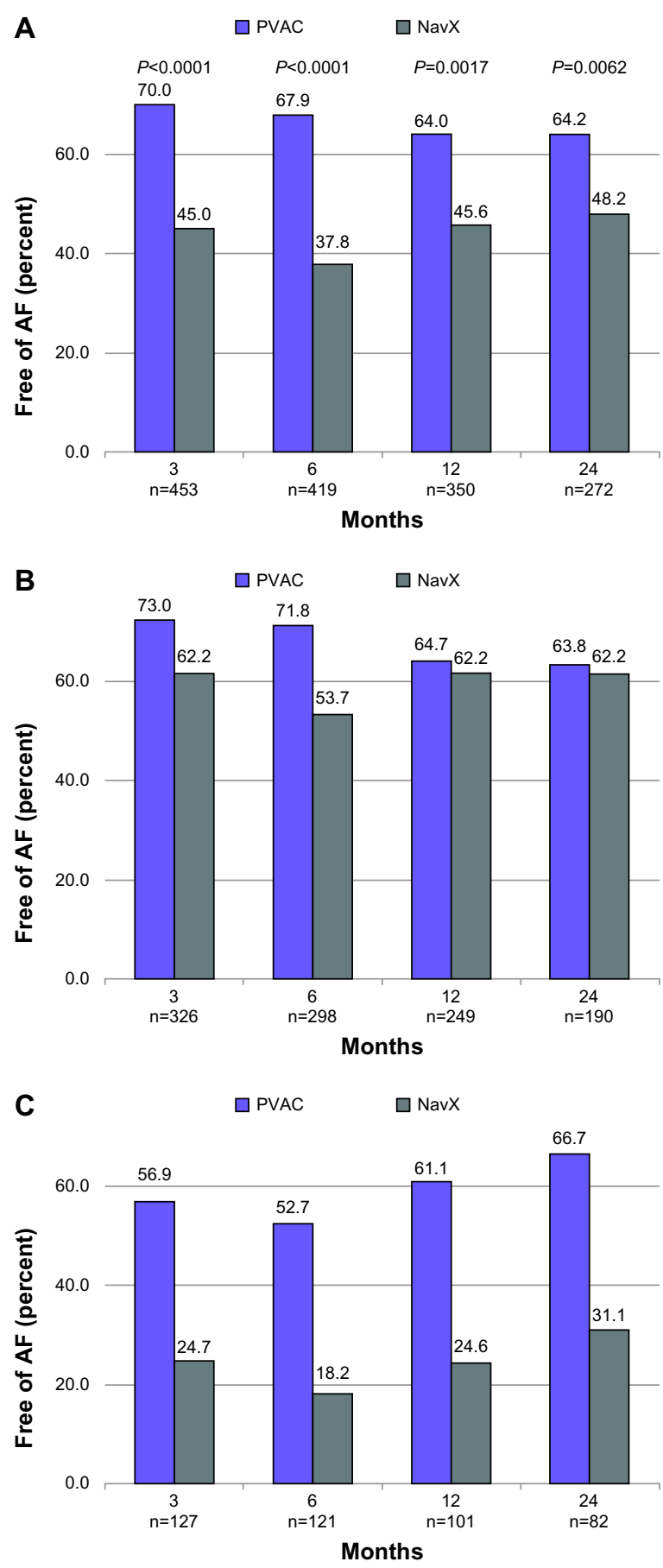

Figure 2 Percent of patients free from AF at different time points during follow-up. Notes: Blue bars indicate patients treated with the PVAC; grey bars are patients treated with NavX-guided point-by-point ablation. (A) All patients; (B) patients with paroxysmal AF; and (C) patients with persistent/long-lasting persistent AF. Abbreviations: PVAC, pulmonary vein ablation catheter; AF, atrial fibrillation; n, number.

\section{Predictors of successful ablation}

Predictors of outcomes were analyzed at 12 months for the entire patient collective. The improved outcomes with PVAC compared with NavX-guided ablation were confirmed $(P=0.017)$, as were the higher rates of AF-free survival 
post-ablation in patients with PAF when compared to those with persistent/long-lasting persistent AF $(P<0.0001)$. A univariate regression analysis showed that the type of AF, ablation method, and the number and duration of ablations were significant predictors of long-term AF-free survival, together with ejection fraction (Table 3 ). The predictive value of the type of $\operatorname{AF}(P=0.0002)$ and the number of ablations $(P<0.00001)$ were confirmed in a multivariate regression analysis.

\section{Complications}

There were no deaths. Two posterior cerebral infarcts occurred in the PVAC group within 2 days of the procedure. In both cases, patients recovered, and long-term neurocognitive performance was not affected. Three pericardial tamponades occurred with PVAC and four with NavX. In each group, there was one post-procedural femoral aneurysm that needed intervention. One case of pericardial effusion occurred in each group. No phrenic nerve injuries and no esophageal injuries were recorded.

In a separate analysis of a subgroup of the PVAC population, CT data from 49 patients and 192 PVs were analyzed for the presence of PV stenosis 6 months from the procedure. One mild case of PV stenosis (left superior pulmonary vein; a $<50 \%$ reduction in $\mathrm{PV}$ diameter) was identified in these patients.

\section{Discussion}

The results presented here from a large patient cohort treated in our center under conditions of actual care showed that PVAC is associated with favorable rates of AF-free survival

Table 3 Univariate analysis of predictors of long-term freedom from ablation

\begin{tabular}{llll}
\hline Variable & $\begin{array}{l}\text { Odds } \\
\text { ratio }\end{array}$ & $\begin{array}{l}\text { 95\% confidence } \\
\text { interval }\end{array}$ & P-value \\
\hline Age & 0.9998 & $0.9809-\mathrm{I} .0189$ & 0.9795 \\
Sex & $\mathrm{I} .2962$ & $0.88 \mathrm{II}-\mathrm{I} .9067$ & $0.186 \mathrm{I}$ \\
Hypertension & 0.9896 & $0.6820-\mathrm{I} .4360$ & 0.9563 \\
Coronary heart disease & 0.7892 & $0.5365-\mathrm{I} .16 \mathrm{II}$ & 0.2288 \\
LA size & 0.9698 & $0.9367-\mathrm{I} .004 \mathrm{I}$ & 0.0796 \\
EF & $\mathrm{I} .0295$ & $\mathrm{I} .005 \mathrm{I}-\mathrm{I} .0545$ & 0.0164 \\
Ablation method & 0.6988 & $0.54 \mathrm{I}-0.90 \mathrm{II}$ & 0.0056 \\
AF type & 0.4836 & $0.3506-0.6670$ & $<0.000 \mathrm{I}$ \\
Duration of AF at inclusion & 0.9855 & $0.9342-\mathrm{I} .0395$ & 0.5917 \\
Number of ablations & 0.3448 & $0.2406-0.4944$ & $<0.000 \mathrm{I}$ \\
Antiarrhythmic drugs post- & $\mathrm{I} .19$ & $0.7164-\mathrm{I} .9820$ & 0.5003 \\
ablation & & & $0.006 \mathrm{I}$ \\
Duration of ablation & 0.9939 & $0.9895-0.9983$ & \\
procedure & & & \\
\hline
\end{tabular}

Abbreviations: LA, left atrium; $E F$, ejection fraction; $A F$, atrial fibrillation. over a mean follow-up of 26 months. Notably, the PVAC procedure was highly successful in long-lasting persistent AF, with a significantly greater percentage of freedom from $\mathrm{AF}$ at 24 months in PVAC-treated patients than in patients treated by point-by-point ablation. In addition, the data confirmed the short fluoroscopy and procedure times with PVAC that have been reported by other investigators in various study settings. ${ }^{9,10}$

To our knowledge, the duration of follow-up in our cohort is the longest reported to date for PVAC, particularly in patients with persistent/long-lasting persistent $\mathrm{AF}$. The rates of freedom from PAF after 12 months of follow-up were highly similar to those reported for the technology in a recent meta-analysis. ${ }^{15}$ Interestingly, the rates remained at similar levels throughout the rest of the follow-up, which indicates that most AF recurrences happen early - an observation that has been made earlier both for $\mathrm{PVAC}^{16}$ and for other ablation techniques. ${ }^{17}$ The phenomenon may be related to pathology rather than to the technology used. If patients at greatest risk of AF recurrence tend to experience the first occurrence within the first 12 months, then patients who remain AF-free for a year may have a different pathology, making them less likely to develop AF over longer periods of time. The underlying differences in pathology would warrant further research and thorough analyses of patients pre- and post-ablation.

As this was a nonrandomized observational study, direct comparisons between the two groups shall be made with some caution. Within the limitations of the study design, we note the significant differences in success rates between PVAC and point-to-point ablation. These differences were greatest in patients with persistent/long-lasting persistent AF. In this group, 12-month rates of AF-free survival after PVAC ablation were $>15$ percentage points higher than what two earlier studies have reported. ${ }^{18,19}$ It appears unlikely that underreporting of events during follow-up would be a reason for these remarkably high success rates, as long-term rates for our patients in the NavX group were not different from those in other studies. Some of the low rates observed with pointby-point ablation may be attributable to the mapping methods used to confirm PVI in the earlier cases, but this is unlikely to account for all of the differences between the systems. The number of patients with persistent/long-lasting persistent AF in our cohort was 82 , which is more than twice the number in the studies cited. The greater rates of freedom from AF with PVAC than with point-by-point ablation in these patients is remarkable, and we can only speculate the reasons for these results. The depth of the lesions created with PVAC 
can be influenced by the bipolar:unipolar ratio, ${ }^{20}$ however, any explanation remains unproven at present, and we note that the total number of patients with persistent/long-lasting persistent AF treated with PVAC is still relatively small.

There were large and statistically significant differences between the groups in terms of the number of applications and the total procedure and fluoroscopy times, all of which were in favor of PVAC. While the differences in our center were greater than some others have reported, ${ }^{21}$ the finding of shorter times, especially with respect to fluoroscopy times associated with PVAC, is consistent with the findings from several other investigator teams in different study settings. ${ }^{9} 10,19,22$

Differences between the groups at baseline may account for part of the differences observed during the study. However, when analyzed separately, procedure times with PVAC remained shorter for all types of AF. One reason for these short times is that no separate mapping catheters are needed when using PVAC. More patients had persistent/longlasting persistent $\mathrm{AF}$ and more complex procedures were necessary in the group using point-by-point ablation. Persistent / long-lasting persistent AF typically needs additional linear lesions to interrupt re-entrant wavelets, and often a roofline and a mitral line in addition to ensure long-term freedom of AF recurrences. ${ }^{4}$ Thus, the main factor is most likely the complexity of the point-by-point ablation procedure itself, even when using high-quality mapping systems. The rationale for the design of the anatomically designed catheter was to enable the generation of reliable contiguous transmural lesions over long distances. Our shorter procedure times corroborate the soundness of these considerations.

Comparing NavX with NavX Fusion (Figure 3), it is not clear that procedure and fluoroscopy times improved with the change from NavX to NavX Fusion in our experience. The integration of CT images into 3D mapping systems is intended to simplify the creation of lesions and to shorten procedure and fluoroscopy times. In part, the lack of differences may be due to the learning curve with the new CTFusion system, ${ }^{23}$ although the integrated system reduced the number of applications without an obvious learning curve.

The safety profiles were favorable for both procedures. In particular, we found very low rates of PV stenosis, which was recently flagged as a possible complication of PVAC

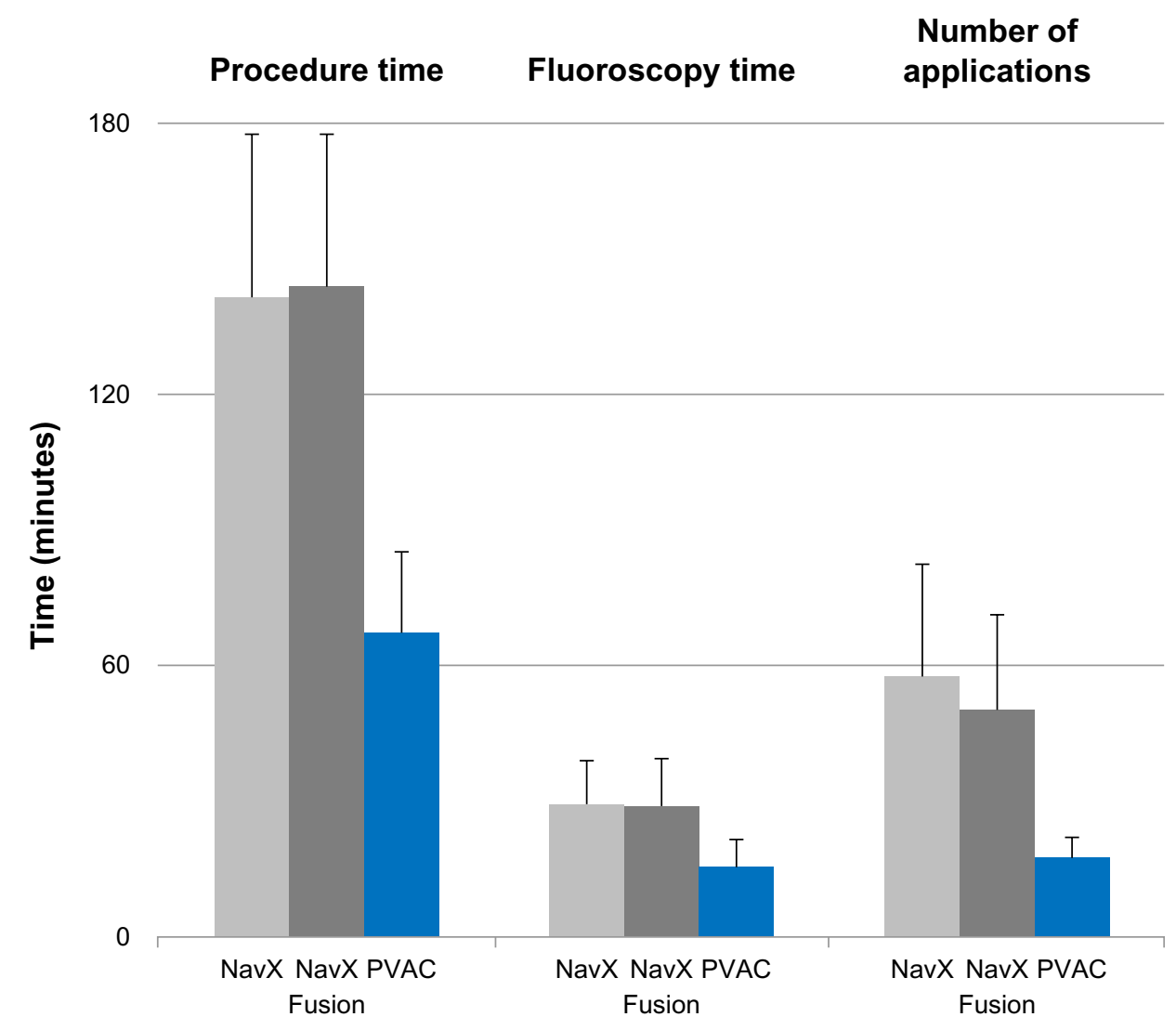

Figure 3 Procedure and fluoroscopy times, and number of applications for ablation guided by NavX and NavX Fusion, as well as PVAC ablation, respectively. Notes: Lines indicate SD. Differences were significant for all comparisons between PVAC and NavX or NavX Fusion. No significant differences were found between NavX and NavX Fusion.

Abbreviations: PVAC, pulmonary vein ablation catheter; SD, standard deviation. 
ablation. ${ }^{24}$ We did not systematically assess PV stenosis in all patients, but a retrospective analysis of 192 PVs showed only one mild case, corresponding to an incidence rate of $0.5 \%$ overall. This is considerably lower than the rate of $7 \%$, as reported in $410 \mathrm{PVs}$ in the study by von Bary et al. ${ }^{24}$ Other investigators have reported no PV stenosis in smaller patient groups. ${ }^{10,21}$ Detailed imaging and anatomical analysis of the PV anatomy is clearly important in reducing the risk of complications. All patients in our center undergo CT/MRI scans as a matter of routine to define the PV anatomy before the ablation procedures - a procedure that may have contributed to the low rate of PV stenosis that was observed.

Recently, there have been concerns about the potential for subclinical intracranial embolic events during PVIs that go unrecognized in everyday clinical practice, but that can be detected with brain MRI. ${ }^{14}$ Although no data on clinical thromboembolisms are available at present, ${ }^{25}$ a greater potential for subclinical events with the PVAC catheter has been suggested, as compared with other RF ablation methods. ${ }^{22,26,27}$ PVAC relies on passive circulatory cooling from blood flow without active irrigation during "off-periods" of duty-cycled RF-current delivery, and it has been questioned whether thrombus formation and charring can be minimized routinely by relying on this mechanism with no irrigation. ${ }^{28}$

In our retrospective analysis, thromboembolic events were recorded, but no MRI data on embolic lesions were available. There were two cases of cerebral infarcts among the 388 patients in the PVAC group within 2 days of the procedure. The relationship of these events to PVAC is unclear. Rates of around $1 \%$ neurologic events, including symptomatic transient ischemic attack/stroke, with duty-cycled RF ablation were recently reported in a large survey. ${ }^{29}$ These rates are in the same range as those reported with conventional $\mathrm{RF}^{30,31}$ Asymptomatic cerebral infarction rates of $\sim 14 \%$ with irrigated-tip catheters have been reported. ${ }^{32}$ Recently, the multicenter Evaluation of the Incidence of Cerebral Lesions Post Pulmonary Vein Ablation Catheter (ERACE) study ${ }^{33}$ showed that applying procedural changes to multielectrode radiofrequency ablation significantly reduced the incidence of asymptomatic cerebral emboli to $1.7 \%$, which is as low as the reported rates of any technology. Multicenter studies such as the ongoing PRECISION GOLD trial (ClinicalTrials.gov identifier NCT01767558 ${ }^{34}$ ) comparing the long-term clinical safety of conventional and duty-cycled multipolar ablation will be needed to lay the issue to rest.

\section{Limitations}

This was a single-center retrospective study, and the individual physician's experience and choice of ablation method for individual patients may have influenced outcomes. The two treatment groups were not balanced for all variables at baseline, with a greater percentage of persistent/long-lasting persistent AF patients in the NavX group and higher rates of mitral insufficiency in the group treated with PVAC. Procedure times for PAF are typically shorter than for other forms, which would have favored the PVAC group for these outcomes. Mitral insufficiency is linked to increased risk of developing $\mathrm{AF},{ }^{35}$ but it is difficult to say how such differences between the groups may have affected the outcomes.

The observational nature and consequential enrollment mean that the data represent a historical comparison, and that ablation procedures from the mid-2000s were included in the analysis. AF ablation methods and the operators' experience have progressed with time. On the one hand, this is a weakness of the analysis, but on the other hand, it permits a view of the dynamic, real world of AF ablation, as performed over a long time period. The consequential enrollment may have affected the outcomes, but we believe the comparison retains validity. Over a study population of $>500$ patients and 6 years, initial learning curves will have mostly evened out for both techniques.

The follow-up time of 24 months does not quite meet the recent definition of $>36$ months for long-term freedom from $\mathrm{AF}^{36}$ and it may have been too short to detect differences in long-time safety. However, in contrast to several other long-term studies, monitoring for AF after 1 year was no less thorough than during the first 12 months of follow-up. Moreover, the number of patients ablated with PVAC was an order of magnitude larger than in published randomized studies. Most follow-up visits utilized 24-hour Holter analyses, and the rates of PAF may be underestimated in our data. ${ }^{37}$ Four-day Holter analyses at all time points might have increased detection rates. Finally, no specific safety studies were conducted, except for the subset of patients assessed for PV stenosis; subclinical embolic events were not monitored.

\section{Conclusion}

In this large cohort of patients treated as per clinical practice, PVAC ablation was associated with similar or superior long-term rates of AF-free survival compared with point-by-point ablation using conventional 3D mapping, and it was associated with significantly shorter procedure and fluoroscopy times. The safety profiles were favorable for both techniques. Data on embolic lesions were not collected, and this issue would need to be evaluated in separate studies. 


\section{Acknowledgments}

The preparation of the work for publication was supported by an unrestricted grant from Medtronic. The authors thank Pelle Stolt $\mathrm{PhD}$ for assistance with drafting the manuscript.

\section{Author contributions}

All authors were involved in the ablation procedures and in the collection and analysis of data. SGS was responsible for the production of the manuscript. All authors contributed toward and approved the final draft.

\section{Disclosure}

The conduct of this study and the analysis of the data received no industry sponsorship. SGS has received research support from Ablation Frontiers and from Medtronic. The authors report no other conflicts of interest in this work.

\section{References}

1. Camm AJ, Kirchhof P, Lip GY, et al; European Heart Rhythm Association; European Association for Cardio-Thoracic Surgery. Guidelines for the management of atrial fibrillation: the Task Force for the Management of Atrial Fibrillation of the European Society of Cardiology (ESC). Eur Heart J. 2010;31(19):2369-2429.

2. Kirchhof P, Auricchio A, Bax J, et al. Outcome parameters for trials in atrial fibrillation: executive summary. Eur Heart J. 2007;28(22): 2803-2817.

3. Lip GY, Golding DJ, Nazir M, Beevers DG, Child DL, Fletcher RI. A survey of atrial fibrillation in general practice: the West Birmingham Atrial Fibrillation Project. Br J Gen Pract. 1997;47(418):285-289.

4. Knecht S, Hocini M, Wright M, et al. Left atrial linear leasions are required for successful treatment of persistent atrial fibrillation. Eur Heart J. 2008;29(19):2359-2366.

5. Boersma LV, Wijffels MC, Oral H, Wever EF, Morady F. Pulmonary vein isolation by duty-cycled bipolar and unipolar radiofrequency energy with a multielectrode ablation catheter. Heart Rhythm. 2008;5(12):1635-1642.

6. Spitzer SG, Karolyi L. Catheter ablation of atrial fibrilliaton - current status and future directions. Applied Cardiopulmonary Pathophysiology. 2009;13:291-299.

7. Wieczorek M, Hoeltgen R, Akin E, Salili AR, Oral H, Morady F. Results of short-term and long-term pulmonary vein isolation for paroxysmal atrial fibrillation using duty-cycled bipolar and unipolar radiofrequency energy. J Cardiovasc Electrophysiol. 2010;21(4):399-405.

8. Scharf C, Boersma L, Davies W, et al. Ablation of persistent atrial fibrillation using multielectrode catheters and duty-cycled radiofrequency energy. J Am Coll Cardiol. 2009;54(15):1450-1456.

9. Bulava A, Haniš J, Sitek D, et al. Catheter ablation for paroxysmal atrial fibrillation: a randomized comparison between multielectrode catheter and point-by-point ablation. Pacing Clin Electrophysiol. 2010;33(9): 1039-1046.

10. Bittner A, Mönnig G, Zellerhoff S, et al. Randomized study comparing duty-cycled bipolar and unipolar radiofrequency with point-bypoint ablation in pulmonary vein isolation. Heart Rhythm. 2011;8(9): 1383-1390.

11. World Medical Association. WMA Declaration of Helsinki - Ethical Principles for Medical Research Involving Human Subjects. Amended by the 59th World Medical Association General Assembly, Seoul, October 2008. Ferney-Voltaire, France: World Medical Association; 2008. Available from: http://www.wma.net/en/30publications/10policies/b3/index. html.pdf. Accessed June 8, 2013.
12. Tada H, Oral H, Sticherling C, et al. Double potentials along the ablation line as a guide to radiofrequency ablation of typical atrial flutter. J Am Coll Cardiol. 2001;38(3):750-755.

13. European Heart Rhythm Association (EHRA), European Cardiac Arrhythmia Society (ECAS), American College of Cardiology (ACC), et al. HRS/EHRA/ECAS expert Consensus Statement on catheter and surgical ablation of atrial fibrillation: recommendations for personnel, policy, procedures and follow-up. A report of the Heart Rhythm Society (HRS) Task Force on catheter and surgical ablation of atrial fibrillation. Heart Rhythm. 2007;4(6):816-861.

14. Gaita F, Caponi D, Pianelli M, et al. Radiofrequency catheter ablation of atrial fibrillation: a cause of silent thromboembolism? Magnetic resonance imaging assessment of cerebral thromboembolism in patients undergoing ablation of atrial fibrillation. Circulation. 2010;122(17): 1667-1673.

15. Andrade JG, Dubuc M, Rivard L, et al. Efficacy and safety of atrial fibrillation ablation with phased radiofrequency energy and multielectrode catheters. Heart Rhythm. 2012;9(2):289-296.

16. Mulder AA, Wijffels MC, Wever EF, Boersma LV. Freedom from paroxysmal atrial fibrillation after successful pulmonary vein isolation with pulmonary vein ablation catheter-phased radiofrequency energy: 2-year follow-up and predictors of failure. Europace. 2012;14(6):818-825.

17. Weerasooriya R, Khairy P, Litalien J, et al. Catheter ablation for atrial fibrillation: are results maintained at 5 years of follow-up? J Am Coll Cardiol. 2011;57(2):160-166

18. Mulder AA, Balt JC, Wijffels MC, Wever EF, Boersma LV. Safety of pulmonary vein isolation and left atrial complex fractioned atrial electrograms ablation for atrial fibrillation with phased radiofrequency energy and multi-electrode catheters. Europace. 2012;14(10):1433-1440.

19. Tivig C, Dang L, Brunner-La Rocca HP, Özcan S, Duru F, Scharf C. Duty-cycled unipolar/bipolar versus conventional radiofrequency ablation in paroxysmal and persistent atrial fibrillation. Int J Cardiol. 2012;157(2):185-191.

20. Wijffels MC, Van Oosterhout M, Boersma LV, et al. Characterization of in vitro and in vivo lesions made by a novel multichannel ablation generator and a circumlinear decapolar ablation catheter. $J$ Cardiovasc Electrophysiol. 2009;20(10):1142-1148.

21. Beukema RJ, Elvan A, Smit JJ, Delnoy PP, Misier AR, Reddy V. Pulmonary vein isolation to treat paroxysmal atrial fibrillation: conventional versus multi-electrode radiofrequency ablation. J Interv Card Electrophysiol. 2012;34(2):143-152.

22. Khaykin Y, Zarnett L, Friedlander D, et al. Point-by-point pulmonary vein antrum isolation guided by intracardiac echocardiography and $3 \mathrm{D}$ mapping and duty-cycled multipolar AF ablation: effect of multipolar ablation on procedure duration and fluoroscopy time. J Interv Card Electrophysiol. 2012;34(3):303-310.

23. KarolyiL, OttoT, RämmlerC, KadalieCT, SpitzerSG. Singlecentererfahrung mit der NavX-gestützten linksatrialen Substratmodifikation bei Patienten mit Vorhofflimmern [Single-centre experience with NavX-supported left atrial substrate modification in patients with atrial fibrillation]. Clin Res Cardiol Suppl. 2008;3(1):113-117. German.

24. von Bary C, Weber S, Dornia C, et al. Evaluation of pulmonary vein stenosis after pulmonary vein isolation using a novel circular mapping and ablation catheter (PVAC). Circ Arrhythm Electrophysiol. 2011;4(5):630-636.

25. Hegland D, Piccini JP, Goldstein LB, Daubert JP. Cerebral magnetic resonance findings in asymptomatic patients after atrial fibrillation catheter ablation: cause for alarm or further study? J Cardiovasc Electrophysiol. 2011;22(9):969-972.

26. Gaita F, Leclercq JF, Schumacher B, et al. Incidence of silent cerebral thromboembolic lesions after atrial fibrillation ablation may change according to technology used: comparison of irrigated radiofrequency, multipolar nonirrigated catheter and cryoballoon. J Cardiovasc Electrophysiol. 2011;22(9):961-968.

27. Herrera Siklódy C, Deneke T, Hocini M, et al. Incidence of asymptomatic intracranial embolic events after pulmonary vein isolation: comparison of different atrial fibrillation ablation technologies in a multicenter study. J Am Coll Cardiol. 2011;58(7):681-688. 
28. Steinberg JS, Mittal S. Intracranial emboli associated with catheter ablation of atrial fibrillation: has the silence finally been broken? J Am Coll Cardiol. 2011;58(7):689-691.

29. Scharf C, Ng GA, Wieczorek M, et al. European survey on efficacy and safety of duty-cycled radiofrequency ablation for atrial fibrillation. Europace. 2012;14(12):1700-1707.

30. Cappato R, Calkins H, Chen SA, et al. Updated worldwide survey on the methods, efficacy, and safety of catheter ablation for human atrial fibrillation. Circ Arrhythm Electrophysiol. 2010;3(1):32-38.

31. Oral H, Chugh A, Ozaydin M, et al. Risk of thromboembolic events after percutaneous left atrial radiofrequency ablation of atrial fibrillation. Circulation. 2006;114(8):759-765.

32. Sakamoto T, Kumagai K, Nishiuchi S, et al. Predictors of asymptomatic cerebral infarction associated with radiofrequency catheter ablation for atrial fibrillation using an irrigated-tip catheter. Europace. 2013;15(3): 332-338.

33. Verma A, Debruyne P, Nardi S, et al; ERACE Investigators. Evaluation and reduction of asymptomatic cerebral embolism in ablation of atrial fibrillation, but high prevalence of chronic silent infarction: results of the evaluation of reduction of asymptomatic cerebral embolism trial. Circ Arrhythm Electrophysiol. 2013;6(5):835-842.
34. Medtronic Atrial Fibrillation Solutions. PRECISION GOLD Post Market Study in Europe of Pulmonary Vein Ablation Catheter (PVAC GOLD). Available from: http://clinicaltrials.gov/show/NCT01767558. NLM identifier: NCT01767558. Accessed December 6, 2013.

35. Grigioni F, Avierinos JF, Ling LH, et al. Atrial fibrillation complicating the course of degenerative mitral regurgitation: determinants and longterm outcome. J Am Coll Cardiol. 2002;40(1):84-92.

36. Calkins H, Kuck KH, Cappato R, et al. 2012 HRS/EHRA/ECAS Expert Consensus Statement on Catheter and Surgical Ablation of Atrial Fibrillation: recommendations for patient selection, procedural techniques, patient management and follow-up, definitions, endpoints, and research trial design. Europace. 2012;14(4):528-606.

37. Mulder AA, Wijffels MC, Wever EF, Kelder JC, Boersma LV. Arrhythmia detection after atrial fibrillation ablation: value of incremental monitoring time. Pacing Clin Electrophysiol. 2012;35(2):164-169.
Research Reports in Clinical Cardiology

\section{Publish your work in this journal}

Research Reports in Clinical Cardiology is an international, peerreviewed, open access journal publishing original research, reports, editorials, reviews and commentaries on all areas of cardiology in the clinic and laboratory. The manuscript management system is completely online and includes a very quick and fair peer-review system.

\section{Dovepress}

Visit http://www.dovepress.com/testimonials.php to read real quotes from published authors. 